\title{
Pengaruh Indeks Risiko Sanitasi Terhadap Kejadian Stunting di Kecamatan Moyo Utara
}

\author{
Iga Maliga $^{1^{*}}$, Herni Hasifah ${ }^{2}$, Rafi’ah $^{1}$, Gladeva Yugi Antari $^{3}$, Ana Lestari ${ }^{3}$ \\ ${ }^{1}$ Program Studi S1 Keperawatan, STIKES Griya Husada Sumbawa Jln.Unter Katimis Sumbawa, NTB 84312, \\ Indonesia \\ ${ }^{2}$ Program Studi S1 Kesehatan Masyarakat, STIKES Griya Husada Sumbawa Jln.Unter Katimis Sumbawa, NTB \\ 84312, Indonesia \\ ${ }^{3}$ Program Studi D3 Kebidanan, STIKES Griya Husada Sumbawa Jln.Unter Katimis Sumbawa, NTB 84312, \\ Indonesia \\ *Corresponding author: maliga07stikesghs@gmail.com
}

Info Artikel:Diterima 1 Agustus 2021 ; Direvisi 15 Desember 2021 ; Disetujui 19 Desember 2021

Tersedia online : 8 Februari 2022 ; Diterbitkan secara teratur : Februari 2022

Cara sitasi (Vancouver): Maliga I, Hasifah H, Antari GY, Rafi'ah R, Lestari A. Pengaruh Indeks Risiko Sanitasi Terhadap Kejadian Stunting di Kecamatan Moyo Utara. Jurnal Kesehatan Lingkungan Indonesia [Online]. 2022 Feb;21(1):50-58. https://doi.org/10.14710/jkli.21.1.50-58.

\begin{abstract}
ABSTRAK
Latar belakang: Sanitasi lingkungan menjadi salah satu faktor yang mempengaruhi derajat kesehatan masyarakat. Salah satu dampak dari buruknya kesehatan lingkungan adalah angka kejadian stunting pada balita.Penelitian ini bertujuan untuk melihat adanya pengaruh antara indeks risiko sanitasi dengan kejadian stunting di Kecamatan Moyo Utara, Kabupaten Sumbawa.

Metode: Suatu penelitian observasional analitik dengan disain cross sectional yang dilakukan pada bulan Maret tahun 2021 di Kecamatan Moyo Utara Kabupaten Sumbawa NTB. Sampel diambil dengan teknik simple random sampling dengan perhitungan menggunakan rumus slovin dengan taraf kesalahan 5\% didapatkan sampel sebanyak 40 orang.

Hasil: karakteristik responden menunjukkan bahwa mayoritas anak responden yang terkena stunting berjenis kelamin perempuan $60 \%$, sisanya laki-laki. Rentang usia 3-4 tahun mendominasi usia anak responden yang menderita stunting sebanyak 40\%, dan yang paling minoritas pada rentang usia $0-2$ tahun sebesar $10 \%$. Mayoritas responden merupakan ibu rumah tangga sebanyak 52,5\%. Berdasarkan hasil analisis Indeks Risiko Sanitasi dengan menggunakan EHRA, sanitasi di wilayah penelitian masuk dalam kategori risiko sanitasi tinggi dan sangat tinggi. Hasil uji regresi linear menunjukkan bahwa ada pengaruh yang signifikan antara risiko sanitasi dengan kejadian stunting pada masa pandemic dengan nilai signifikansi $<0,001$ dengan nilai koefisien regresi sebesar 0,6 .

Simpulan:Terdapat pengaruh antara indeks risiko sanitasi dengan kejadian stunting di Kecamatan Moyo Utara dengan persen pengaruh yang cukup signifikan antara risiko sanitasi dengan kejadian stunting yaitu sebesar $60 \%$.
\end{abstract}

Kata kunci: Lingkungan; Kesehatan; Sanitasi; Stunting

\section{ABSTRACT}

Title: Effect of Sanitation Risk Index on Stunting Incidence in North Moyo District

Background: Environmental hygiene is one of the factors that influence the level of public health. One of the effects of poor environmental hygiene is stunting in children under the age of five. This study aims to determine the impact of hygiene risk indicators on the incidence of stunting in the Sumbawa Regency's North Moyo area. 
Methods: This study is an analytical observational study using quantitative data. This study used a crosssectional approach. This study using survey and interview methods. The survey was conducted in March 2021 in the North Moyo area of NTB's Sumbawa Regency. The samples in this study were extracted using a simple random sampling technique calculated using Slovin's formula with an error rate of 5\%. A sample of 40 people was obtained.

Results: Respondent characteristics showed that the majority of respondents' children affected by stunting were 60 years old and the rest were boys. The age range of 34 years dominates the age of respondents who suffer from stunting by $40 \%$, and the most minority is in the age range of 02 years by $10 \%$. The majority of respondents are housewives, as much as 52.5\%. Based on the Sanitation Risk Index analysis results using the EHRA method, sanitation in the research area is categorized as high and very high sanitation risk. The linear regression test results showed a significant effect between sanitation risk and the incidence of stunting with a significance value of $<0.001$ with a regression coefficient of 0.6 .

Conclusion: There is an influence between the sanitation risk index and the incidence of stunting in North Moyo District with a significant effect between the sanitation risk and the incidence of stunting, which is $60 \%$.

Keywords: Environment; Health; Sanitation; Stunting

\section{PENDAHULUAN}

Pencapaian akses sanitasi sangat penting untuk mempercepat kemajuan bidang kesehatan. Menurut data World Bank (2017) cakupan orang yang menggunakan layanan sanitasi yang dikelola di dunia masih sebesar $44,987 \%$ dari populasi. ${ }^{1}$ Sedangkan di Indonesia menurut data UNICEF menyebutkan bahwa $69 \%$ air yang dikonsumsi dirumah tangga terkontaminasi oleh fases. Nusa tenggara barat sebagai salah satu provinsi di Indonesiamemiliki ratarata akses bawah dari rata-rata nasional yaitu $60 \%$ sedangkan di NTB baru mencapai $53 \%{ }^{2}$ Hal ini mengunjukkan bahwa masih kurangnya kesadaran masyarakat tentang sanitasi lingkungan.

Kebersihan lingkungan adalah suatu keadaan yang menunjukkan kesehatan lingkungan, seperti kebersihan rumah tangga, sistem kebersihan, dan penyediaan air bersih. Kebersihan lingkungan untuk memenuhi kebutuhan lingkungan yang sehat dan nyaman. ${ }^{3}$ Hygiene meliputi unsur kebersihan lingkungan yang menitikberatkan pada penerapan budaya hidup bersih untuk mencegah masyarakat terkontaminasi langsung dengan sampah dengan tujuan meningkatkan kesehatan manusia. Menumbuhkan gaya hidup bersih sangat penting. Jika tidak, ada risiko kebersihan. Risiko sanitasi adalah membahayakan kualitas hidup, kesehatan dan lingkungan yang disebabkan oleh akses yang buruk ke pelayanan dan fasilitas kebersihan dan kebiasaan sanitasi yang buruk. Higiene yang buruk merupakan salah satu faktor yang dapat menyebabkan terhambatnya pertumbuhan pada balita. ${ }^{3}$

Stunting merupakan kondisi terhambatnya tumbuh kembang pada anak maupun balita (bayi dibawah lima tahun) akibat dari kekurangan gizi kronis. Hal ini akan mempengaruhi tinggi badan anak atau panjangnya terlalu pendek untuk anak seusianya. Bayi mungkin mengalami kekurangan gizi di dalam kandungan dan tahap awal kelahiran, namun stunting baru terjadi setelah bayi berusia 2 tahun. Perawakan pendek (keterlambatan perkembangan) dan sangat pendek (pertumbuhan kerdil yang parah) mengacu pada panjang badan $(\mathrm{PB} / \mathrm{U})$ atau tinggi badan yang berbeda usia dibandingkan dengan standar WHOMGRS (Multicenter Growth Reference Study) 2006. ${ }^{4}$ Stunting merupakan masalah gizi kronis yang disebabkan oleh kurangnya asupan gizi dalam waktu cukup lama akibat pemberian makanan yang tidak sesuai dengan kebutuhan gizi. Keadaan ini terjadi akibat dari faktor lingkungan dan faktor manusia (host) yang didukung oleh kekurangan asupan zat zat gizi. $^{5}$

Terkait dengan stunting dan masalah kesehatan lingkungan, banyak penelitian yang membuktikan bahwa kesehatan lingkungan telah memberikan kontribusi yang signifikan dalam pengentasan stunting, salah satunya adalah akses fasilitas air minum, toilet dan sabun (CTP) bersih bagi anak-anak di Bangladesh untuk mencuci tangan. ${ }^{6}$ Sanitasi lingkungan yang buruk pada akses air bersih, penggunaan jamban yang tidak layak dan rendahnya kepatuhan dalam perilaku mencuci tangan memiliki kontribusi terhadap peningkatan penyakit infeksi yang berbasis lingkungan seperti diare, Environmental Enteric Dysfunction (EED) dan cacingan. Penyakit infeksi ini dapat meyebabkan gangguan penyerapan makanan yang berdampak terhadap gangguan gizi dan berdampak secara jangka panjang. Gangguan gizi yang berkepanjangan berpengaruh terhadap pertumbuhan linear balita yang terganggu seperti stunting. ${ }^{26}$

Upaya perbaikan kondisi stunting melalui program intervensi nutrisi yang dilakukan selama ini belum mampu secara optimal. Pelaksanaan evidencebased nutritional interventions tingkat cakupan $90 \%$ hasilnya hanya mampu menekan angka stunting sebesar $15 \%{ }^{7}$ Berdasarkan hasil Kementerian Kesehatan Republik Indonesia tahun 2021, prevalensi stunting di Indonesia sebesar 11,6\%, meskipun secara angka nasional kurang dari $15 \%$ akan tetapi secara regional masih ada beberapa provinsi di Indonesia yang angka prevalensi stuntingnya di atas angka $20 \%$ yaitu, Papua Barat, Sulawesi Barat, Nusa Tenggara Barat (NTB) dan Nusa Tenggara Timur (NTT) ${ }^{8}$ 
Nusa Tenggara Barat (NTB) memiliki angka stunting tertinggi ke dua secara nasional yaitu sebesar $23,4 \%{ }^{8}$ Hal ini mengindikasikan bahwa masalah stunting belum tertangani dengan baik. Hal ini semakin diperparah dengan kondisi pandemic covid 19. Hasil Riskesdas 2013 menunjukkan angka stunting mencapai $37,2 \%$. Hasil survei pemantauan gizi tahun 2017, angka stunting di wilayah Sumbawa sebesar $41,82 \%$, tertinggi di antara 10 kota lain di NTB. Berdasarkan survei Riskesdas 2018, kejadian stunting di Kabupaten Sumbawa menurun 10\% menjadi $31,53 \%$. Mengingat angkanya yang masih tinggi, Pemkab Sumbawa telah menetapkan 37 desa sebagai prioritas penanganan stunting. Hal itu tertuang dalam Keputusan Bupati Sumbawa Nomor 859 Tahun 2020 tentang Penetapan Desa Prioritas Percepatan Pencegahan dan Penanggulangan Stunting melalui Intervensi Gizi Sensitif, dan Gizi Spesifik di Kabupaten Sumbawa.

Kabupaten Sumbawa ditetapkan sebagai salah satu wilayah dengan kasus Kejadian Luar Biasa (KLB) stunting dengan salah satu wilayah kecamatannya adalah Kecamatan Moyo Utara. Hal ini menjadi hal yang sangat penting dalam penentuan masa depan suatu wilayah. Berdasarkan data yang didapatkan dari Puskesmas Kecamatan Moyo Utara pada tahun 2019, bahwa anak balita yang menderita stunting sebanyak 23,65\% di Desa Kukin, 22,01\% di Desa Penyaring, 21,77\% di Desa Pungkit, 21,62\% di Desa Baru, 16,13\% di Desa Songkar dan 15,11\% di Desa Sebewe. Penderita stunting di Desa Kukin Kecamatan Moyo Utara, anak anak dalam kategori pendek dan ada beberapa dalam kategori sangat pendek. Anak yang menderita stunting lebih banyak perempuan dibandingkan laki laki. Sisi lain menunjukkan bahwa berdasarkan hasil penelitian yang dilakukan oleh Maliga (2019), 6 desa yang ada di Kecamatan Moyo Utara merupakan wilayah dengan Indeks Risiko Sanitasi (IRS) dengan kategori tinggi dan sangat tinggi. Hal ini disebabkan oleh buruknya pemahaman masyarakat terkait pentingnya sanitasi terhadap kesehatan. ${ }^{9}$ Selain itu, masyarakat masih cenderung mengabaikan sanitasi lingkungan sehingga berdampak pada tingginya risiko sanitasi yang dihadapi oleh wilayah tersebut. Sampai dengan saat ini, secara ilmiah belum diketahui penyebab pasti terjadinya stunting di wilayah tersebut. Melihat fakta di lapangan tingginya angka stunting bersamaan dengan tingginya indeks risiko sanitasi (IRS) menimbulkan hipotesis awal terkait adanya pengaruh risiko sanitasi kejadian stunting yang ada di wilayah tersebut. Penelitian ini bertujuan untuk mengetahui adanya pengaruh risiko sanitasi dengan kejadian stunting di Kecamatan Moyo Utara.

\section{MATERI DAN METODE}

Penelitian ini merupakan penelitian observasional analitik dengan disain cross sectional yang dilakukan pada bulan Maret tahun 2021 di Kecamatan Moyo Utara Kabupaten Sumbawa NTB.
Pendekatan cross sectional dimana data yang dikumpulkan sekaligus pada suatu saat atau sekali pengambilan data (point time apporach). Sampel diambil dengan teknik simple random sampling dengan menggunakan perhitungan rumus slovin dengan taraf kesalahan 5\%. Hasil perhitungan didapatkan sampel sebanyak 40 orang.

Teknik dalam pengumpulan data menggunakan metode survey dan wawancara. Unit sampling dalam penelitian ini adalah ibu yang memiliki anak yang menderita stunting dengan kriteria dasar sebagai berikut:

1. Anak-anak memiliki berat badan dan tinggi badan dibawah batasan normal

2. Anak-anak yang umur 6 bulan -5 tahun

3. Anak-anak yang tidak sedang menderita penyakit infeksi

4. Anak-anak yang orang tuanya bersedia menjadi responden selama penelitian dilakukan

Variabel bebas penelitian ini adalah risiko sanitasi lingkungan yang dikumpulkan menggunakan kuesioner EHRA sedangkan variabel terikatnya adalah kejadian stunting, yang merupakan data sekunder dari hasil pengukuran oleh petugas kesehatan setempat, kemudian divalidasi dengan melakukan pengukur kembali balita terpilih menggunakan microtoise. Pada variabel indeks risiko sanitasi, terdapat lima sub-variabel yang diteliti yaitu ; 1) penerapan PHBS; 2) Kepemilikan sarana jamban; 3) Kepemilikan sarana pembuangan air limbah; dan 4) Kepemilikan tempat sampah serta 5) Kepemilikan sarana air bersih. Kejadian stunting mengacu pada data sekunder dari Puskesmas Wilayah Kerja Moyo Utara bulan Januari tahun 2021. Sedangkan data indeks risiko sanitasi didapatkan melalui teknik survey dan wawancara menggunakan metode Environmental Health Risk Assessment (EHRA). Kualitas sarana sanitasi ditentukan dengan teknik skoring. Penentuan standar Indeks Risiko Sanitasi (IRS) berdasarkan pada total indeks risiko maksimal sebesar 266 dan indeks risiko sanitasi minimal 160 . Secara detail dijelaskan pada Tabel 1. berikut;

Tabel 1. Kategori Area Berisiko Indeks Risiko Sanitasi (IRS)

\begin{tabular}{lcc}
\hline Item & $\begin{array}{c}\text { Batas } \\
\text { Nilai } \\
\text { Risiko }\end{array}$ & Keterangan \\
\hline $\begin{array}{l}\text { Akumulasi Indeks Risiko } \\
\text { Maksimum }\end{array}$ & 266 & \\
$\begin{array}{l}\text { Akumulasi Indeks Risiko } \\
\text { Minimum }\end{array}$ & 160 & \\
Kategori Area Berisiko & Batas & Batas Atas \\
& Bawah & \\
Kurang Berisiko & 160 & 187 \\
Berisiko Sedang & 188 & 214 \\
Risiko Tinggi & 215 & 242 \\
Risiko Sangat Tinggi & 243 & 269 \\
\hline
\end{tabular}

(sumber : Laporan EHRA Kabupaten Gresik, 2015) 
Data penelitian diolah secara deskriptif dan pengujian hipotesis dengan menggunakan uji regresi sederhana dengan bantuan aplikasi SPSS for windows versi 16.0 Metode wawancara digunakan untuk menguatkan hasil kuesioner yang dijawab oleh responden. Wawancara menggunakan panduan wawancara terstruktur.

\section{HASIL DAN PEMBAHASAN}

Penelitian ini dilakukan di wilayah Moyo Utara.Wilayah kerja Moyo Utara menjadi salah satu wilayah yang angka stuntingnya masih sangat tinggi. Tercatat sebanyak 159 anak dengan rentang usia $0-5$ tahun memiliki status gizi bermasalah. 120 anak kategori pendek (TB/U), 17 gizi kurang dan risiko gizi lebih (BB/TB) dan 13 anak berat badan sangat kurang $(\mathrm{BB} / \mathrm{U})$, lalu sisanya adalah anak dengan $\mathrm{BB}$ kurang dan normal. Hal ini menjadi tantangan tersendiri bagi pihak PKM Moyo Utara untuk menurunkan angka stunting yang ada di wilayahnya. Di sisi lain dengan hasil penelitian sebelumnya pada wilayah ini juga menunjukkan indeks risiko sanitasi yang masuk dalam kategori tinggi dan sangat tinggi.

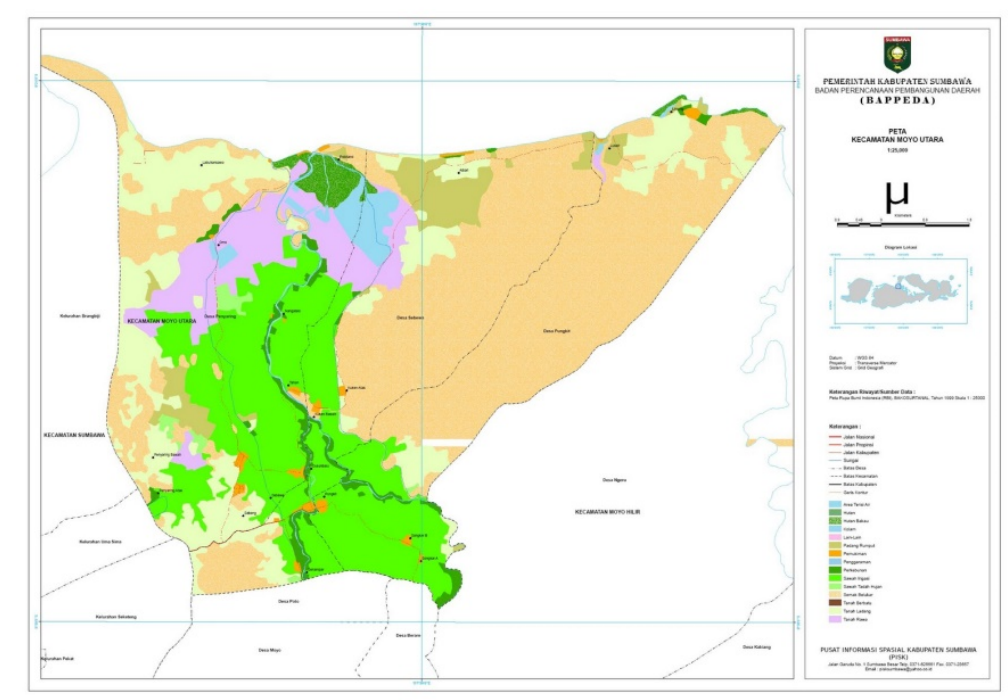

Gambar 1. Lokasi Penelitian Kecamatan Moyo Utara

Penelitian ini dilakukan dengan melibatkan 40 orang responden yang memiliki anak yang masuk dalam kategori stunting di Kecamatan Moyo Utara. Distribusi karakteristik responden meliputi jenis kelamin, usia dan pekerjaan sebagai berikut,

Tabel 2. Distribusi Frekuensi Karakteristik Responden

\begin{tabular}{lcc}
\hline Jenis Kelamin & Frekuensi & Persen (\%) \\
Laki-laki & 16 & 40 \\
perempuan & 24 & 60 \\
\hline
\end{tabular}

\begin{tabular}{lcc}
\hline Rentang Usia (Thn) & & \\
$0-2$ & 4 & 10 \\
$2-3$ & 14 & 35 \\
$3-4$ & 16 & 40 \\
$4-5$ & 6 & 15 \\
\hline
\end{tabular}

\begin{tabular}{lcc}
\hline Pekerjaan & & \\
IRT & 21 & 52.5 \\
Petani & 9 & 22.5 \\
TKW & 2 & 5 \\
Pedagang & 8 & 20 \\
\hline Total & $\mathbf{4 0}$ & $\mathbf{1 0 0 . 0}$ \\
\hline
\end{tabular}

(sumber : Data Primer, 2021)
Berdasarkan Tabel 2, mayoritas responden memiliki distribusi jenis kelamin perempuan hingga $24(60 \%)$ dan sisanya 16 laki-laki $(40 \%)$. Jenis kelamin berhubungan dengan terjadinya retardasi pertumbuhan. Anak laki-laki 2,4 kali lebih mungkin untuk terkena stunting daripada anak perempuan. Ini disebabkan oleh perbedaan komposisi tubuh antara pria dan wanita, yang mempengaruhi kebutuhan nutrisi mereka. Anak perempuan memiliki lebih banyak jaringan adiposa daripada anak laki-laki yang memiliki lebih banyak jaringan otot. Hal ini menyebabkan perbedaan metabolisme antara keduanya dimana otot lebih aktif daripada lemak. Karena otot lebih aktif, mereka membutuhkan lebih banyak energi secara proporsional daripada lemak. Hal ini menunjukkan bahwa pria dan wanita memiliki tinggi, berat dan usia yang sama, tetapi memiliki kebutuhan energi dan nutrisi yang berbeda. ${ }^{27}$

Usia anak responden mayoritas berada pada rentang 3-4 tahun sebanyak 16 orang (40\%). Kekurangan gizi terjadi semenjak bayi masih pada pada kandungan ibunya \& dalam masa awal sehabis bayi lahir, akan namun syarat stunting baru nampak sehabis bayi berusia sekitar dua tahun. Berdasarkan hal tadi bisa disimpulkan bahwa stunting dalam balita baru terlihat pada usia di atas dua tahun. ${ }^{15}$ Mayoritas 
ibu dalam penelitian ini merupakan Ibu Rumah Tangga (IRT) dan yang paling sedikit berprofesi sebagai Tenaga Kerja Wanita (TKW) di luar negeri, sehingga terdapat anak yang dibawah pengasuhan nenek dan kakeknya bukan oleh ibu kandungnya. Pola asuh pemberian makan dan pola asuh pengasuhan sangat mempengaruhi optimalisasi perkembangan balita. Seringkali pola makan yang kurang tepat mempengaruhi status gizi pada balita tersebut. ${ }^{16}$

Tabel 3 menunjukkan bahwa lokasi penelitian dipenuhi dengan sampah tanpa adanya kontrol lebih lanjut oleh masyarakat. Sampah memiliki efek langsung dan tidak langsung seperti pencemaran air, udara dan tanah, meningkatkan efek gas rumah kaca dan menyebabkan penyakit. Dampak tidak langsung dari sampah adalah dapat menjadi sarang vektor atau reservoir bagi kecoa, nyamuk, tikus, dan lain-lain yang menunjukkan lingkungan yang tidak sehat. ${ }^{29}$ Tindakan perbaikan lingkungan sangat diperlukan dan tujuannya agar lingkungan dapat menjadi tempat yang sehat bagi semua makhluk hidup. Sehingga, lingkungan yang sehat dapat mempengaruhi kualitas hidup dan kesehatan masyarakat yang tinggal di sana. $^{28}$

Tabel 3. Kondisi Sanitasi Lingkungan Sekitar Wilayah Penelitian

\begin{tabular}{lc}
\hline \multicolumn{1}{c}{ Kondisi } & Persentase (\%) \\
\hline Sampah bertumpuk di sekitar lokasi & 82.1 \\
Lalat di tumpukan sampah & 69.2 \\
Tikus berkeliaran & 5.1 \\
Vektor Nyamuk & 30.8 \\
Hewan pengganggu mendatangi tumpukan sampah & 53.8 \\
Bau busuk & 5.1 \\
Sampah menyumbat drainase & 7.7 \\
Anak-anak bermain di sekitar tumpukan sampah & 15.4 \\
\hline
\end{tabular}

(Sumber : Data Primer, 2021)

Tabel 4. Gambaran Kondisi Variabel Risiko Sanitasi

\begin{tabular}{|c|c|c|c|c|c|c|}
\hline \multirow{2}{*}{ Variabel } & \multirow{2}{*}{ Jawaban } & \multicolumn{5}{|c|}{ STRATA } \\
\hline & & 0 & 1 & 2 & 3 & 4 \\
\hline \multicolumn{7}{|l|}{ 1. Sumber Air } \\
\hline Sumber terTindungi & Tidak & 25,0 & 43,1 & 53,3 & 46,9 & 42,5 \\
\hline Penggunaan air tak terlindungi. & $\mathrm{Ya}$ & 24,7 & 7,5 & 12,5 & 27,5 & 15,4 \\
\hline Kelangkaan & $\mathrm{Ya}$ & 11,1 & 15,4 &, 0 & 2,5 & 7,7 \\
\hline \multicolumn{7}{|l|}{ 2. Air limbah domestik } \\
\hline Keamanan tangki septik & Tidak & 17,5 & 13,8 & 24,2 & 28,1 & 15,0 \\
\hline Pencemaran tangki septik & $\mathrm{Ya}$ & 96,8 & 100,0 & 100,0 & 96,8 & 100,0 \\
\hline Pencemaran SPAL & $\mathrm{Ya}$ & 84,0 & 97,5 & 90,0 & 70,0 & 82,1 \\
\hline \multicolumn{7}{|l|}{ 3. Persampahan } \\
\hline Tata kelola sampah & Tidak & 82,5 & 98,1 & 94,2 & 94,4 & 92,5 \\
\hline Frekuensi pengangkutan & Tidak memadai & ,0 & 100,0 & 100,0 & ,0 & ,0 \\
\hline Ketepatan pengangkutan & Tidak tepat waktu & ,0 & 100,0 & 100,0 &, 0 & ,0 \\
\hline Pengolahan sampah rumah tangga & Tidak diolah & 45,0 & 70,6 & 61,7 & 76,3 & 80,0 \\
\hline \multicolumn{7}{|l|}{ 4. Genangan air } \\
\hline Genangan air & $\mathrm{Ya}$ & 32,5 & 26,9 & 40,0 & 46,9 & 52,5 \\
\hline \multicolumn{7}{|l|}{ 5. Perilaku Hidup Bersih Sehat (PHBS) } \\
\hline CTPS & Tidak & 80,2 & 55,0 & 65,0 & 92,5 & 94,9 \\
\hline Lantai WC (bebas dari tinja) & Tidak & 26,9 & 27,5 & 38,9 & 48,5 & 29,2 \\
\hline WC bebas dari kecoa dan lalat & Tidak & 25,6 & 37,5 & 33,3 & 54,5 & 25,0 \\
\hline Keberfungsian penggelontor & Tidak & 7,4 & 22,5 & 20,0 & 22,5 & 41,0 \\
\hline Sabun khusus (berada dekat jamban) & Tidak & 19,2 & 37,5 & 11,1 & 24,2 & 20,0 \\
\hline Pencemaran (wadah penyimpanan air) & Ya, tercemar & 71,6 & 82,5 & 87,5 & 77,5 & 61,5 \\
\hline BABS & Ya, BABS & 100,0 & 100,0 & 78,3 & 73,7 & 27,5 \\
\hline
\end{tabular}

(Sumber : Data Primer, 2021) 
Berdasarkan Tabel 4, terlihat bahwa lokasi penelitian menunjukkan hasil yang buruk, sehingga tidak mengherankan jika hasil sanitasi di wilayah ini sangat buruk. Hal ini berdampak pada naiknya risiko sanitasi yang akan berdampak pada kesehatan masyarakat termasuk stunting. Mungkin perlu ditekankan untuk mencegah stunting. Ini adalah peningkatan kebersihan berbasis masyarakat. Program sanitasi total berbasis masyarakat (STBM) terdiri dari 5 pilar menjadi salah satu langkah tepat dalam menurunkan angka kejadian stunting. Pilar STBM tersebut adalah stop buang air besar sembarangan (BABS), cuci tangan pakai sabun (CTPS), pengelolaan air minum dan makanan, pengelolaan sampah, dan pengelolaan limbah cair domestik. ${ }^{13}$

Tabel 5. Kumulatif Indeks Risiko Sanitasi

\begin{tabular}{clcccc}
\hline No & \multicolumn{1}{c}{ Desa } & Cluster & $\begin{array}{c}\text { Nilai } \\
\text { risiko }\end{array}$ & Kategori Risiko & $\begin{array}{c}\text { Indeks } \\
\text { Risiko }\end{array}$ \\
\hline 1 & Penyaring dan Sebewe & 0 & 216 & Tinggi & 3 \\
2 & Baru Tahan & 1 & 277 & Sangat Tinggi & 4 \\
3 & Kukin & 2 & 281 & Sangat Tinggi & 4 \\
4 & Pungkit & 3 & 245 & Sangat Tinggi & 4 \\
5 & Songkar & 4 & 233 & Sangat Tinggi & 4 \\
\hline
\end{tabular}

(Sumber : Data Primer, 2021).

Tabel 6. Hasil Uji Regresi Linear Sederhana

\begin{tabular}{lcc}
\hline & Item & Nilai \\
\hline Nilai Koefisien Regresi & 0.601 \\
Nilai Signifikansi & $<0.001$ \\
Nilai Konstant B & 35.420 \\
\hline
\end{tabular}

\begin{tabular}{rc}
\hline $\mathbf{N}$ & $\mathbf{4 0}$ \\
\hline
\end{tabular}

(Sumber : Data Primer, 2021).

Berdasarkan hasil survei lapangan, desa yang menjadi lokasi survei memiliki kategori risiko sanitasi sangat tinggi. Proses clustering dilakukan di 6 desa dari 0 sampai 4 . Hanya dua desa yang masuk dalam kategori berisiko tinggi dan empat desa lainnya berada dalam kategori sangat tinggi. Daerah dengan kategori risiko sanitasi tinggi dan sangat tinggi dapat menyebarkan penyakit dan higiene yang buruk. ${ }^{30}$

Hasil penelitian menunjukkan bahwa ada hubungan antara IRS dengan kejadian stunting di wilayah Moyo Utara. Hal ini ditunjukkan dengan nilai signifikansi $<0,001$. Artinya adalah nilai signifikansi $<0,05$ yang menunjukkan bahwa ada hubungan antara risiko higiene dengan stunting. Kelompok anak balita yang stunting seringkali memiliki pola perilaku higiene yang kurang baik. Kebersihan lingkungan yang buruk dan tidak terpenuhinya syarat kesehatan dapat menyebabkan berbagai jenis penyakit lingkungan, antara lain diare, cacingan, ISPA, dan infeksi saluran pencernaan. Analisis data stunting dan sanitasi dalam Survei Kehidupan Keluarga Indonesia tahun 2014 menunjukkan bahwa kualitas air dan sanitasi yang buruk dapat menyebabkan munculnya penyakit, terutama penyakit menular dan penyakit akut yang menyebabkan perkembangan anak yang buruk. ${ }^{22}$

Stunting lazimnya disebabkan oleh kekurangan gizi jangka panjang, yang berubah sebagai retardasi pertumbuhan secara kronis. Pengasuhan meliputi metode pemberian makan, kebiasaan kebersihan diri, dan cara ibu mencari pengobatan. Sebuah studi yang dilakukan oleh Yudianti \& Saeni pada tahun 2016 menunjukkan bahwa dibandingkan dengan pola asuh pola makan yang baik, pola asuh pengasuhan yang buruk memiliki risiko 2,4 kali lebih tinggi untuk mengalami stunting. Kawasan pemukiman juga memberikan gambaran tentang praktik kebersihan yang dilakukan oleh masyarakat. Pedesaan dan perkotaan mencerminkan kondisi sanitasi, dibandingkan dengan perkotaan (33\%), prevalensi anak di bawah 5 tahun yang stunting di perdesaan $(40 \%)$ lebih tinggi. ${ }^{10}$ Angka kejadian stunting pada anak pada keluarga dengan kepala rumah tangga yang tidak berpendidikan lebih tinggi dari mereka yang berada pada keluarga dengan kepala rumah tangga yang berpendidikan lebih tinggi sebanyak 17 kali lipat. ${ }^{11}$

Terdapat hubungan yang bermakna antara stunting, diare, dan kejadian ISPA pada balita dengan air bersih, sanitasi, sampah dan pembuangan sampah rumah tangga. ${ }^{12}$ Kementerian Kesehatan Republik Indonesia juga menyatakan bahwa ada tiga hal yang perlu diperhatikan untuk mencegah retardasi pertumbuhan yaitu gizi, pendidikan, perbaikan sanitasi dan akses air bersih. Hasil penelitian Herawati pada tahun 2020 semakin mendukung hal tersebut. Kualitas fasilitas medis dan perilaku residen berhubungan dengan perkembangan stunting dan merupakan faktor risiko. Kualitas CTPS ibu tidak 
berhubungan dengan perkembangan retardasi pertumbuhan, tetapi merupakan faktor risiko. ${ }^{14}$

Kondisi sampah yang ditemukan di lokasi rumah responden belum memenuhi standar kebersihan yang memadai. Masih banyak sampah yang menumpuk tanpa pemilahan dan pengelolaan lebih lanjut. Dari 40 responden yang mengalami stunting, 90\% tinggal di rumah tangga dengan kualitas sanitasi yang tidak memenuhi persyaratan Deklarasi Kesehatan, dan memiliki kualitas kebersihan yang memenuhi persyaratan. Namun, anak dari empat responden menderita stunting, kemungkinan karena faktor lain penyebab stunting yang tidak diteliti dalam penelitian ini. Kebersihan yang layak akan sangat membantu pemerintah memperkuat upaya kesehatan lingkungan rumah mereka. Kegagalan untuk mencapai hasil yang optimal dengan meningkatkan akses ke kebersihan rumah dapat menyebabkan risiko paparan bahaya kesehatan lingkungan. Kebersihan yang buruk berhubungan erat dengan prevalensi penyakit umum, terutama diare. Tingginya prevalensi penyakit diare dikaitkan dengan kebersihan yang buruk, pengelolaan lingkungan yang buruk, kepadatan penduduk yang tinggi, dan pasokan air bersih yang buruk. ${ }^{17}$

Hasil wawancara dengan responden tentang kebersihan rumah dipastikan terkonfirmasi. Tujuh puluh lima persen responden menyatakan tidak terlalu memperhatikan sampah, air limbah domestik, dan juga kebersihan rumah tangga. Mereka masih hanyafokus pada kebersihan sumber air yang dimiliki. Hal ini sesuai dengan penelitian Khumaidi tahun 2019, yang menemukan bahwa persepsi masyarakat tentang pentingnya mengolah limbah cair manusia (limbah rumah tangga) masih tidak sejalan dengan persepsi tentang pentingnya air bersih yang meningkat. Aspek air bersih merupakan aspek terpenting dari indikator higiene orang yang disurvei. Padahal semua indikator kebersihan berperan penting dalam mencegah stunting di masyarakat. ${ }^{18}$

Berlandaskan hasil uji regresi menunjukkan nilai koefisien signifikansi sebesar $<0.001$. Maknanya ialah terdapat pengaruh yang signifikan antara kejadian stunting dengan kondisi resiko sanitasi di Kecamatan Moyo Utara. Pola asuh pada anak stunting dipengaruhi oleh 3 aspek utama ialah pola asuh intervensi nutrisi serta pola asuh psikososial dan pola sanitasi lingkungan. Pengasuhan anak yang menekankan pada intervensi gizi meliputi suplementasi asam folat, suplementasi keseimbangan protein ibu, suplementasi kalsium ibu selama kehamilan, dorongan menyusui, suplementasi nutrisi pelengkap yang tepat, suplementasi vitamin A dan zinc. ${ }^{7}$ Praktek asuhan psikososial didefinisikan selaku sikap yang dipraktekkan oleh penjaga (bunda, ayah, nenek, ataupun orang lain) dalam membagikan stimulus serta sokongan emosional yang diperlukan buat proses kembang anak.

Faktor lain yang mempengaruhi stunting adalah lingkungan. Jika lingkungan tempat tinggal anak tidak menerapkan pola hidup sehat, maka kesehatan anak seperti gizi dan stunting otomatis akan terdampak ${ }^{19}$. Faktor higiene dan akses air bersih antara lain kebersihan dan akses air bersih, membuat anak lebih sadar akan risiko penyakit menular. ${ }^{20}$ Untuk itu, sebaiknya membiasakan diri untuk mencuci tangan dengan sabun dan air mengalir. Kebersihan lingkungan rumah mempengaruhi perkembangan stunting pada anak di bawah usia lima tahun. Studi tahun 2019 oleh Purwanti dan Nurfita menemukan bahwa faktor sosial ekonomi, demografi, dan lingkungan berpengaruh signifikan terhadap kejadian stunting anak. ${ }^{21}$ Terdapat pengaruh yang cukup signifikan antara risiko sanitasi dengan kejadian stunting yaitu sebesar $60 \%$. Berdasarkan hasil uji regresi menunjukkan nilai koefisien signifikansi sebesar $<0.001$. Dapat disimpulkan bahwa terdapat hubungan yang cukup kuat antara IRS dengan kejadian stunting di wilayah Moyo Utara. Akses ke toilet sehat dan sumber air bersih yang memenuhi isyarat kesehatan merupakan faktor risiko keterlambatan pertumbuhan setelah menyesuaikan variabel historis untuk riwayat penyakit menular, riwayat pemberian makanan pendamping, dan pemantauan pertumbuhan. ${ }^{23}$ Model pengendalian stunting juga dapat dilakukan dengan penguatan kemampuan keluarga dalam mencegah penyakit menular, pemanfaatan kebun sebagai sumber gizi keluarga, dan peningkatan kebersihan lingkungan. ${ }^{24}$ Mengingat kondisi stunting saat ini wilayah Kabupaten Sumbawa masih cukup tinggi maka sudah seharusnya proses pencegahan stunting harus diperkuat dari segala aspek termasuk aspek sanitasi lingkungan. ${ }^{25}$

\section{SIMPULAN}

Permasalahan stunting pada balita memiliki dampak yang signifikan pada tumbuh kembang anak. Kesimpulan dalam penelitian ini adalah 1) Sebanyak 24 orang $(60 \%)$ responden berjenis kelamin perempuan, usia anak responden mayoritas pada rentang 3-4 tahun sebanyak 16 orang (40\%). Sebanyak 21 orang (52.5\%) merupakan Ibu Rumah Tangga (IRT), Risiko Sanitasi dari 6 desa 4 desa masuk dalam kategori sangat tinggi. Selanjutnya, 2) Ada pengaruh yang signifikan antara risiko sanitasi dengan kejadian stunting dengan nilai signifikansi $<0,001$ dengan nilai persen pengaruh sebesar $60 \%$. Rekomendasi untuk penelitian selanjutnya adalah dapat dibuat perbandingan kelas kasus dengan kelas kontrol untuk lebih memperlihatkan pengaruh risiko sanitasi tinggi dengan wilayah risiko sanitasi rendah terhadap kejadian stunting.

\section{UCAPAN TERIMAKASIH}

Terima kasih atas bantuan pemerintah Kecamatan Moyo Utara Kabupaten Sumbawa, NTB atas kesediaannya membantu peneliti dalam proses penelitian. 


\section{DAFTAR PUSTAKA}

1. The World Bank Data. WHO/UNICEF Joint Monitoring Programme ( JMP ) for Water Supply, Sanitation and Hygiene. Diakses melalaui

https://data.worldbank.org/indicator/SH.STA.S

MSS.ZS pada tanggal 1 Agustus 2021, pukul 20.52 WITA

2. UNICEF. 2021. WASH Challenges in Indonesia. Tersedia pada link https://www.unicef.org/indonesia/media/10061/f ile/WASH $\% 20$ Acts $\% 20$ Vol. \%201\%20MarApr\%202021.pdf diakses pada tanggal 1 Agustus 2021 pada pukul 20.53.

3. Sidhi AN, Raharjo M, Dewanti NAY. Hubungan Kualitas Sanitasi Lingkungan dan Bakteriologis Air Bersih Terhadap Kejadian Diare Pada Balita di Wilayah Kerja Puskesmas Adiwerna Kabupaten TegaL. Jurnal Kesehatan Masyarakat (Undip). 2016 Aug;4(3):665-676.

4. Kemenkes RI. Situasi Balita Pendek Di Indonesia. Kementeri Kesehat Republik Indones. 2016;ISSN 2442-(Hari anak Balita 8 April):110.

5. Rudert C. Malnutrition In Asia. Vientiane: UNICEF East Asia Pacific; 2014.

6. Parkes. Beyond Malnutrition. Environ Health Perspect. 2014;122(11):298-303.

7. Masrul, M. Gambaran Pola Asuh Psikososial Anak Stunting dan Anak Normal di Wilayah Lokus Stunting Kabupaten Pasaman dan Pasaman Barat Sumatera Barat. Jurnal Kesehatan Andalas, 2019: 8(1), 112. https://doi.org/10.25077/jka.v8i1.978

8. Kementerian Kesehatan Republik Indonesia. Laporan Akuntabilitas Kinerja Tahun 2020. Kementerian Kesehatan Tahun 2019 Kementerian Kesehatan.

9. Maliga, I., \& Darmin, D. Analisis Penilaian Risiko Kesehatan Lingkungan dengan Menggunakan Pendekatan Environmental Health Risk Assessment (EHRA) di Kecamatan Moyo Utara. Media Ilmiah Teknik Lingkungan (MITL), 2020:5(1), 16-26. https://doi.org/10.33084/mitl.v5i1.1235

10. Yudianti Y, Saeni RH. Pola Asuh Dengan Kejadian Stunting Pada Balita di Kabupaten Polewali Mandar. J Kesehat Manarang. 2017;2(1):21.https://doi.org/10.33490/jkm.v2i1. 9

11. Rahayu B, Darmawan S. Hubungan Karakteristik Balita, Orang Tua, Higiene dan Sanitasi Lingkungan Terhadap Stunting pada Balita. Binawan Student J. 2019;1(1):22-7. Available from: http://journal.binawan.ac.id/bsj/article/view/46

12. Hasanah S, Handayani S, Wilti IR. Hubungan Sanitasi Lingkungan Dengan Kejadian Stunting Pada Balita di Indonesia (Studi Literatur). JK3L.
2021Aug.31 [cited 2021Dec.12];2(2):83-94. https://doi.org/10.25077/jk31.2.2.83-94.2021

13. Fauzan, A. R. Q. Hubungan Sanitasi dengan Kejadian Stunting pada Balita. Jurnal Medika Hutama, 3: 2021: 01 Oktober), 1299-1303.

14. Herawati H, Anwar A, Setyowati DL. Hubungan Sarana Sanitasi, Perilaku Penghuni, dan Kebiasaan Cuci Tangan Pakai Sabun (CTPS) oleh Ibu dengan Kejadian Pendek (Stunting) pada Batita Usia 6-24 Bulan di Wilayah Kerja Puskesmas Harapan Baru, Samarinda. Jurnal Kesehatan Lingkungan Indonesia. 2020 Apr;19(1):7-15.

https://doi.org/10.14710/jkli.19.1.7-15.

15. Solihin, R.D.M., Anwar, F, dan Sukandar, D. KAitan Antara Status Gizi, Perkembangan Motorik, pada Anak Usia Prasekolah. Jurnal Penelitian Gizi dan Makanan, Juni 2013 Vol 36 (1) ; 62-72

16. Sari, Milda Riski Nirmala \& Ratnawati, Leersia Yusi. Hubungan Pengetahuan Ibu tentang Pola Pemberian Makan dengan Status Gizi Balita di Wilayah Kerja Puskesmas Gapura Kabupaten Sumenep. Amerta Nutrition, 2018: 2(2), 182188.

https://doi.org/10.20473/amnt.v2.i2.2018.182$\underline{188}$

17. Purwoko, S. Indikator Air Layak Minum dan Sanitasi Layak dalam Mendukung Upaya Kesehatan Lingkungan di Rumah Tinggal.Universitas Nahdalatul Ulama Surabaya Journal, 2018 : 1(1), 62-67.

18. Khumaidi, A., Rahayu, T., \& Darmiyanti, L. Sosialisasi Penanganan Air Limbah Rumah Tangga Di Karawang. Jurnal SOLMA, 2019: $8(2)$, 287. https://doi.org/10.29405/solma.v8i2.3165

19. Laili, A. N. Pengaruh Sanitasi Di Lingkungan Tempat Tinggal Terhadap Kejadian Stunting Pada Balita. Jurnal Kebidanan, 2019: 8(1), 2832. https://doi.org/10.47560/keb.v8i1.192

20. Purwanti, R., \& Nurfita, D. Review Literatur: Analisis Determinan Sosio Demografi Kejadian Stunting Pada Balita di Berbagai Negara Berkembang. Buletin Penelitian Kesehatan, 2019: 47(3), 153-164. https://doi.org/10.22435/bpk.v47i3.1349

21. Yuliani Soeracmad, Y. S. Hubungan Sanitasi Lingkungan Rumah Tangga Dengan Kejadian Stunting Pada Anak Balita Di Puskesmas Wonomulyo Kabupaten polewali Mandar Tahun 2019. J-KESMAS: Jurnal Kesehatan Masyarakat, 2019: $\quad 5(2), \quad 138$. https://doi.org/10.35329/jkesmas.v5i2.519

22. Khairiyah, D., \& Fayasari, A. Perilaku higiene dan sanitasi meningkatkan risiko kejadian stunting balita usia 12-59 bulan di Banten. Ilmu Gizi Indonesia, 2020: 3(2), 123. https://doi.org/10.35842/ilgi.v3i2.137

23. Hasan, A., \& Kadarusman, H. Akses ke Sarana 
Sanitasi Dasar sebagai Faktor Risiko Kejadian Stunting pada Balita Usia 6-59 Bulan. Jurnal Kesehatan, 2019: $10(3), \quad 413$. https://doi.org/10.26630/jk.v10i3.1451

24. Kusumawati, E., Rahardjo, S., \& Sari, H. P. Model pengendalian faktor risiko stunting pada anak bawah tiga tahun. Kesmas: Jurnal Kesehatan Masyarakat Nasional (National Public Health Journal), 2015:9(3), 249-256. https://doi.org/10.21109/kesmas.v9i3.572

25. Widiastuti, A., \& Winarso, S. P. Program PMT dan Grafik Pertumbuhan Balita Pada Masa Pandemi Covid. Jurnal Sains Kebidanan, 2021: 3(1), 30-35.

26. Cumming, O., \& Cairncross, S. Can water, sanitation and hygiene help eliminate stunting? Current evidence and policy implications. In Maternal and Child Nutrition. 2016 https://doi.org/10.1111/mcn.12258

27. Angelina F, Christin, Perdana, A.A., dan Humairoh. Faktor Kejadian Stunting Balita
Berusia 6-23 bulan di Provinsi Lampung. Jurnal Dunia Kesmas, 2018 Juli:7(3).

28. Celesta, A. G., \& Fitriyah, N. Overview Basic Sanitation In Payaman Village, Bojonegoro District 2016. Jurnal Kesehatan Lingkungan, 2019 . 11(2),

83. https://doi.org/10.20473/jkl.v11i2.2019.83-9

29. Tentama, F., Hastuti, S. K. W., Mulasari, S. A., Rokhmayanti, Sulistyawati, Sukesi, T. W., \& Nurdjannah, S. Pemberdayaan masyarakat dalam pengelolaan sampah untuk pengendalian vektor penyakit di Modalan, Banguntapan. Prosiding Seminar Nasional Hasil Pengabdian Kepada Masyarakat Universitas Ahmad Dahlan 2020: November, 379-388.

30. Mutiarani, P. T. Studi Sanitasi Kapal Kargo dan Keberadaan Bakteri E. Coli pada Makanan Jadi di Wilayah Pelabuhan Tanjung Perak Surabaya. Jurnal Kesehatan Lingkungan 2020: 9(2), 111121.

C2022. This open-access article is distributed under the terms and conditions of the Creative Commons Attribution-ShareAlike 4.0 International License. 